\title{
Incidence and profile of benign epithelial tumors of salivary glands from a single center in Northeast of Brazil
}

\author{
Breno Washington Joaquim de Santana ${ }^{1}$, Leorik Pereira da Silva ${ }^{2}$, Marianna Sampaio Serpa ${ }^{3}$, Mariana de \\ Albuquerque Borges ${ }^{4}$, Sérgio Ricardo Soares de Moura ${ }^{4}$, Márcia Maria Fonseca da Silveira ${ }^{5}$, Ana Paula \\ Veras Sobral 5 \\ ${ }^{1}$ DDS, Research collaborator, School of Dentistry, University of Pernambuco, Camaragibe, PE, Brazil \\ ${ }^{2}$ DDS, PhD, Adjunct Professor, Institute of Health and Biotechnology, Federal University of Amazonas, Coari, AM, Brazil \\ ${ }^{3}$ DDS, PhD, A.C.Camargo Cancer Center, São Paulo - SP, Brazil \\ ${ }^{4}$ MD, Staff Pathologist, Department of Pathology, Cancer Hospital of Pernambuco, Recife, PE, Brazil \\ ${ }^{5}$ DDS, PhD, Associate Professor, Postgraduate Program in Dentistry, School of Dentistry, University of Pernambuco, Camara- \\ gibe, PE, Brazil
}

Correspondence:

Postgraduate Program in Dentistry,

School of Dentistry, University of Pernambuco

Av. General. Newton Cavalcanti, 1650 - Tabatinga

Camaragibe, Zip code: 54756-220, Recife/PE, Brazil

marcia.m.f.s@hotmail.com

Received: 03/06/2020

Accepted: 16/11/2020

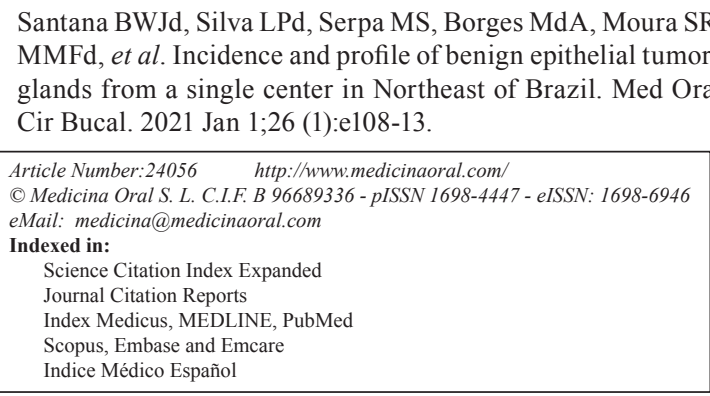

\begin{abstract}
Background: Benign tumors of the salivary glands are a group of lesions with varied histopathological and clinical spectrum. The aim was to determine the incidence and clinicopathological characteristics of benign salivary gland neoplasms diagnosed between 2007 and 2016 in a single center located in northeastern Brazil.

Material and Methods: Records regarding sex, age, anatomical location, histopathological subtype and treatment were retrieved, and data were analyzed using the Stata/IC software (version 12.0).

Results: There were above 7,100 cases of neoplasms in the head and neck region, of which 403 corresponded to salivary gland neoplasms. Of these, 238 (59\%) were benign, being pleomorphic adenoma (PA) the most frequent neoplasm $(\mathrm{n}=178 ; 74.8 \%)$, followed by Warthin's tumor $(\mathrm{WT})(\mathrm{n}=23 ; 9.7 \%)$. Overall, most cases occurred in females $(n=136 ; 57.1 \%)$ and age ranged from 11 to 83 years. The parotid gland $(n=188 ; 79 \%)$ was the most common anatomical site, and all patients were treated by surgical excision. Of the cases diagnosed as PA, malignant transformation to carcinoma ex-pleomorphic adenoma (CAEXPA) occurred in 7 (3.9\%) cases.

Conclusions: The present study confirmed the clinical and demographic profile of benign salivary gland neoplasms, which contributes to the continuous knowledge of current data about these lesions.
\end{abstract}

Key words: Salivary gland, benign neoplasms, epidemiology. 


\section{Introduction}

Salivary gland neoplasms represent about $3-6 \%$ of all head and neck neoplasms and their annual global incidence is approximately $0.4-13.5$ per 100,000 people. Most cases are benign, and present great histopathological diversity. Currently, the World Health Organization (WHO) recognizes 11 subtypes of benign epithelial tumors of the salivary glands, though, some variants such as lymphadenoma, sebaceous adenoma and ductal papilloma are extremely rare (1-7). Large series report that approximately $64-80 \%$ of primary neoplasms of epithelial origin occur in the parotid, $7-11 \%$ in the submandibular gland, less than $1 \%$ in the sublingual gland and $9-23 \%$ in minor salivary glands (2-8).

As for their nature, usually more than $50 \%$ are benign, reaching a prevalence up to $86 \%$ (7). Most cases occur between the fourth and seventh decades of life and women are more affected (2-7). Pleomorphic adenoma (PA) is the most common benign salivary gland neoplasm, comprehending about $50 \%$ of the cases, and Warthin's tumor (WT) is the second one, representing 4 to $15 \%$ of all salivary gland neoplasms $(2-6,8-11)$. Furthermore, benign neoplasms with enduring evolution and history of recurrences can undergo malignant transformation. For instance, PA can evolve to carcinoma ex-pleomorphic adenoma (CAEXPA), which diminishes the survival of the patient (12).

Epidemiological studies that assess the incidence and characteristics of these tumors help to update scientists and health professionals worldwide. Thus, this retrospective study aimed to analyze the cases of benign salivary gland neoplasms in a referral hospital in northeastern Brazil in order to keep data renewed.

\section{Material and Methods}

The study was evaluated and approved by the local Research Ethics Committee (REC/HCP - no 2.774.008). Medical records of patients attended between 2007 and 2016 at the Cancer Hospital of Pernambuco were retrieved, and for those diagnosed with benign salivary gland neoplasm, clinicopathological characteristics (sex, age, anatomical location, histopathological subtype and treatment performed) were collected. Records had to report histopathological diagnosis of salivary gland neoplasm and all clinical data to be included in the study. The cases diagnosed as benign salivary gland neoplasms were re-assessed by an oral and maxillofacial pathologist in order to confirm and adequate final histological diagnosis with the current WHO classification (1). For this, $5 \mu \mathrm{m}$ sections of each case were stained with hematoxylin and eosin and evaluated under light microscopy. Nomenclature and criteria used to reclassify the cases were based on the descriptions summarized by the current WHO classification of salivary gland tumors (1). When in doubt about the diagnosis, a second pathologist was consulted. There were no disagreements related to the reclassification and no case was excluded. After histological evaluation, 3 cases previously denominated "oxyphilic adenoma" were renamed as oncocytoma, and 9 cases diagnosed as "monomorphic adenoma" were reclassified to canalicular adenoma ( 1 case) and the other 8 to basal cell adenoma. In addition, 6 cases of PA were reclassified to myoepithelioma.

Database was mounted and analyzed using the Stata/IC software (version 12.0; StataCorp, CollegeStation, TX), with a descriptive analysis of the sex, age, anatomical location and treatment. The results obtained were assigned to a table with their respective absolute and relative frequencies.

\section{Results}

In nine years, approximately 230,635 lesions were diagnosed in the referred hospital. Of these, approximately 7,100 were cases of head and neck neoplasms, of which $403(5.7 \%)$ were of salivary gland neoplasms. There were 238 cases of benign salivary gland neoplasm, which corresponded to $59 \%$ of all salivary gland neoplasms and $3.3 \%$ of the head and neck tumors. Most cases were diagnosed in females $(\mathrm{n}=136 ; 57.1 \%)$ and age varied between 11 and 83 years, with an average of 48 years-old $(\mathrm{SD} \pm 16)$. PA was the most frequent neoplasm $(\mathrm{n}=178 ; 74.8 \%)$, followed by WT $(\mathrm{n}=23 ; 9.7 \%)($ Table 1$)$.

Table 1: Age group and gender distribution of benign salivary gland neoplasms.

\begin{tabular}{|c|c|c|c|c|c|c|c|c|c|c|c|c|c|c|}
\hline \multirow{2}{*}{$\begin{array}{l}\text { Benign salivary } \\
\text { gland neoplasms }\end{array}$} & \multirow{2}{*}{$\begin{array}{c}\text { Age } \\
\text { range }\end{array}$} & \multirow{2}{*}{$\begin{array}{c}\text { Mean } \\
\text { Age }\end{array}$} & \multicolumn{8}{|c|}{ Age groups } & \multicolumn{2}{|c|}{ Gende $r$} & \multicolumn{2}{|c|}{ TOTAL } \\
\hline & & & $0-19$ & $20-29$ & 30-39 & 40-49 & $50-59$ & $60-69$ & $\geq 70$ & NI & $\mathbf{F}$ & $\mathbf{M}$ & $\mathbf{N}$ & $\%$ \\
\hline Pleomorphic adenoma & $11-83$ & 45 & 10 & 16 & 38 & 43 & 36 & 16 & 15 & 4 & 106 & 72 & 178 & 74.8 \\
\hline Warthin's tumor & $21-76$ & 57 & 0 & 1 & 0 & 7 & 3 & 8 & 4 & 0 & 7 & 16 & 23 & 9.7 \\
\hline Basal cell adenoma & $44-83$ & 65 & 0 & 0 & 0 & 2 & 4 & 4 & 7 & 0 & 11 & 6 & 17 & 7.1 \\
\hline Myoepithelioma & $21-75$ & 55 & 0 & 1 & 2 & 2 & 1 & 3 & 4 & 2 & 11 & 4 & 15 & 6.3 \\
\hline Oncocytoma & $39-57$ & 51 & 0 & 0 & 1 & 0 & 2 & 0 & 0 & 0 & 0 & 3 & 3 & 1.3 \\
\hline Canalicular adenoma & 39 & 39 & 0 & 0 & 1 & 0 & 0 & 0 & 0 & 0 & 0 & 1 & 1 & 0.4 \\
\hline Cystadenoma & 66 & 66 & 0 & 0 & 0 & 0 & 0 & 1 & 0 & 0 & 1 & 0 & 1 & 0.4 \\
\hline Total & $11-83$ & $\begin{array}{c}48 \\
S D \pm 16\end{array}$ & 10 & 18 & 42 & 54 & 46 & 32 & 30 & 6 & 136 & 102 & 238 & 100 \\
\hline
\end{tabular}

$\mathrm{F}=$ female; $\mathrm{M}=$ male; $\mathrm{N}=$ number of cases; $\mathrm{NI}=$ not informed; $\mathrm{SD}=$ standard deviation; $\%=$ percentage. 
Benign salivary gland neoplasms occurred more in major salivary glands ( $\mathrm{n}=216 ; 90.8 \%$ ), with the parotid gland being the most common anatomical site $(\mathrm{n}=188 ; 79 \%)$ and PA the most predominant tumor. WT $(\mathrm{n}=23 ; 9.7 \%)$, oncocytoma $(n=3 ; 1.3 \%)$ and cystadenoma $(n=1 ; 0.4 \%)$ affected only the parotid gland. Furthermore, most cases of basal cell adenoma $(\mathrm{n}=16 ; 6.7 \%)$ and myoepithelioma $(\mathrm{n}=12 ; 5 \%)$ also occurred in this anatomical site. Minor salivary glands represented $9.2 \%(\mathrm{n}=22)$ of the cases, with the palate $(\mathrm{n}=13 ; 5.5 \%)$ being the most frequent region, followed by the buccal mucosa $(\mathrm{n}=6 ; 2.5 \%)$. The most common histological diagnosis at both sites was PA (Table 2). Fig. 1 illustrates the main findings of this study. Patients with lesions in the major salivary glands were submitted to fine-needle aspiration prior to surgical treatment, in order to obtain the diagnosis. Seven cases diagnosed as PA and 2 cases diagnosed as WT were considered malignant after surgical resection and his- topathological analysis. Mucoepidermoid carcinoma, adenoid cystic carcinoma and unspecified adenocarcinoma were the definitive diagnoses. As for the tumors located in the minor salivary glands, incisional biopsy was conducted for diagnosis prior to surgical excision. All patients diagnosed with benign salivary gland neoplasms performed a non-radical surgical excision. Preservation of the facial nerve was maintained for all surgeries of the parotid gland. Of the 178 cases diagnosed as PA, malignant transformation to CAEXPA occurred in 7 cases (3.9\%). These cases had a history of PA with one or two recurrences before the transformation and no case was initially diagnosed as malignant (primary CAEXPA). Evolution time until the diagnosis of CAEXPA ranged from 2 to 10 years. Table 3 shows that for previous studies conducted in Brazil the rate of malignant transformation of PA varied from $0-10.8 \%$ in several diagnostic centers.

Table 2: Anatomical site distribution of benign salivary gland neoplasms.

\begin{tabular}{|l|c|c|c|c|c|c|c|c|c|}
\hline \multirow{2}{*}{$\begin{array}{c}\text { Benign salivary gland } \\
\text { neoplasms }\end{array}$} & \multicolumn{3}{|c|}{ Major glands } & \multicolumn{4}{c|}{ Minor glands } & \multicolumn{2}{c|}{ Total } \\
\cline { 2 - 11 } & Parotid & Subm & Subl & Palate & $\begin{array}{c}\text { Buccal } \\
\text { mucosa }\end{array}$ & Lips & $\begin{array}{c}\text { Floor of } \\
\text { the mouth }\end{array}$ & N & \% \\
\hline Pleomorphic adenoma & 133 & 25 & 3 & 11 & 4 & 1 & 1 & $\mathbf{1 7 8}$ & $\mathbf{7 4 . 8}$ \\
\hline Warthin's tumor & 23 & 0 & 0 & 0 & 0 & 0 & 0 & $\mathbf{2 3}$ & $\mathbf{9 . 7}$ \\
\hline Basal cell adenoma & 16 & 0 & 0 & 0 & 1 & 0 & 0 & $\mathbf{1 7}$ & $\mathbf{7 . 1}$ \\
\hline Myoepithelioma & 12 & 0 & 0 & 2 & 1 & 0 & 0 & $\mathbf{1 5}$ & $\mathbf{6 . 3}$ \\
\hline Oncocytoma & 3 & 0 & 0 & 0 & 0 & 0 & 0 & $\mathbf{3}$ & $\mathbf{1 . 3}$ \\
\hline Canalicular adenoma & 0 & 0 & 0 & 0 & 0 & 1 & 0 & $\mathbf{1}$ & $\mathbf{0 . 4}$ \\
\hline Cystadenoma & 1 & 0 & 0 & 0 & 0 & 0 & 0 & $\mathbf{1}$ & $\mathbf{0 . 4}$ \\
\hline $\begin{array}{l}\text { Total } \\
(\%)\end{array}$ & $\mathbf{1 8 8}$ & $\mathbf{2 5}$ & $\mathbf{3}$ & $\mathbf{1 3}$ & $\mathbf{6}$ & $\mathbf{2}$ & $\mathbf{1}$ & $\mathbf{2 3 8}$ & $\mathbf{1 0 0}$ \\
\hline
\end{tabular}

$\mathrm{N}=$ number of cases; Subm= Submandibular gland; Subl= Sublingual gland; $\%=$ percentage.

Table 3: General features of benign salivary gland neoplasms from studies conducted in Brazil (2005-2020).

\begin{tabular}{|c|c|c|c|c|c|c|}
\hline Authors & Region & $\mathbf{N}$ & $\begin{array}{c}\text { Most common } \\
\text { neoplasms }\end{array}$ & $\begin{array}{c}\text { Malignant } \\
\text { transformation } \\
\text { of PA }\end{array}$ & $\begin{array}{l}\text { M:F } \\
\text { ratio }\end{array}$ & $\begin{array}{l}\text { Predominant } \\
\text { anatomic site }\end{array}$ \\
\hline Present study & Northeast & 238 & $\mathrm{PA}>\mathrm{WT}>\mathrm{BCA}$ & $3.9 \%$ & $1: 1.3$ & Parotid \\
\hline Vasconcelos et al. (5) & South & 85 & $\mathrm{PA}>\mathrm{WT}$ & $0 \%$ & $1: 1.1$ & Parotid \\
\hline Da Silva et al. (7) & Northeast and Southeast & 1.322 & $\mathrm{PA}>\mathrm{BCA}>\mathrm{CYS}$ & $3.2 \%$ & $1: 1.6$ & Parotid \\
\hline Bittar et al. (15) & Southeast & 215 & $\mathrm{PA}>\mathrm{WT}$ & $0 \%$ & $1: 1.9$ & Parotid \\
\hline Fonseca et al. (3) & South and Southeast & 369 & $\mathrm{PA}>\mathrm{WT}>\mathrm{CA}$ & $2.5 \%$ & $1: 1.4$ & Parotid \\
\hline De Oliveira et al. (14) & Midwest & 469 & $\mathrm{PA}>\mathrm{WT}$ & $0 \%$ & $1: 1.6$ & Parotid \\
\hline Abrahão et al. (16)* & Southeast & 89 & $\mathrm{PA}>\mathrm{CYS}>\mathrm{CA}$ & $5.3 \%$ & $1: 1.5$ & Palate \\
\hline Ito et al. (17) & South & 335 & $\mathrm{PA}>\mathrm{WT}>\mathrm{MYO}$ & $1.1 \%$ & $1: 1.2$ & Parotid \\
\hline Reinheimer et al. (23) & South & 81 & $\mathrm{PA}>\mathrm{WT}>\mathrm{MYO}$ & $10.8 \%$ & $1: 1.3$ & Parotid \\
\hline Morais et al. (24) & Northeast & 215 & $\mathrm{PA}>\mathrm{BCA}>\mathrm{WT}$ & $1.2 \%$ & $1: 1.8$ & Parotid \\
\hline Cunha et al. (25) & Northeast & 470 & $\mathrm{PA}>\mathrm{WT}>\mathrm{CA} / \mathrm{MYO}$ & $2.3 \%$ & $1: 1.4$ & Parotid \\
\hline
\end{tabular}

*Studied only minor salivary glands; BCA: Basal cell adenoma; CA: Canalicular adenoma; CYS: Cystadenoma; MYO: Myoepithelioma; PA: Pleomorphic adenoma; WT: Warthin's tumor; F: Female; M: Male; N: number of cases of benign tumors; NI: Not informed; \%: Percentage of benign tumors in the study. 


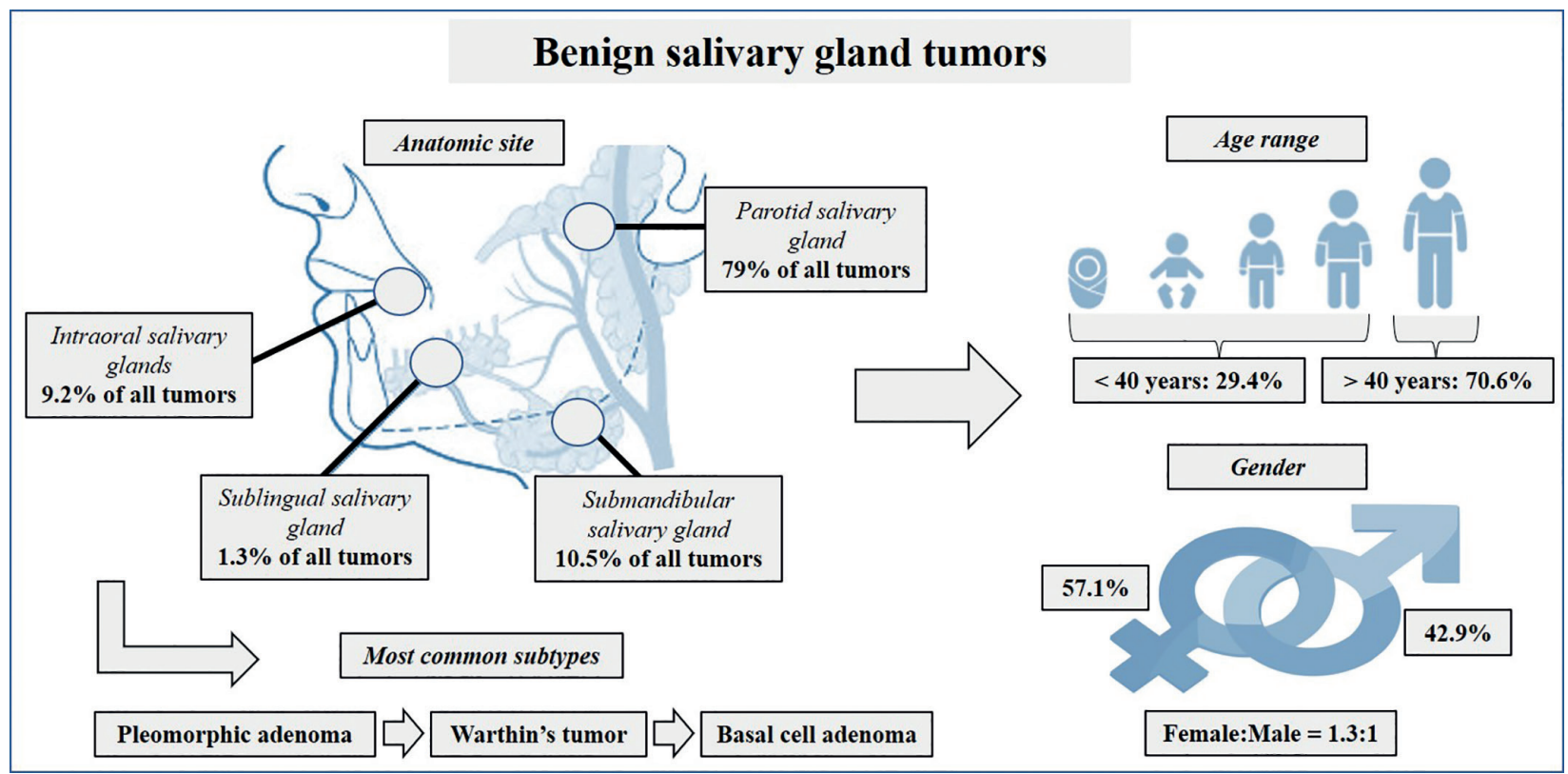

Fig. 1: General clinicopathological findings of benign salivary gland neoplasms.

\section{Discussion}

In the studied hospital, benign salivary gland neoplasms $(n=238 ; 59 \%)$ represented the majority of the cases, being in agreement with worldwide literature (2-15). Furthermore, other studies conducted in Brazil also confirm our findings $(3,5,7,14,16,17)$. In the present study, the average age was 48 years-old ( $\mathrm{SD} \pm 16)$, with a range from 11 to 83 years. Most cases occurred in females and the parotid gland was the most frequent site representing $79 \%$ of the cases. Gao et al. (6) and Da Silva et al. (7) found similar results to ours were most cases of benign salivary gland neoplasm occurred in the 5 th decade of life, females and parotid gland. In contrast, two studies conducted by Tian et al. (2) and Wang et al. (4) found that the male gender was most affected by salivary tumors. This indicates that some divergence may be found in the literature, reinforcing the importance to perform epidemiological studies worldwide and compare their results.

PA was the most common benign neoplasm, representing about $75 \%$ of cases, followed by WT with $9.7 \%$. Corroborating these findings, other studies showed similar results (2-6,8-11,14-16). Nevertheless, in a multicenter study conducted in Brazil, Da Silva et al. (7) observed basal cell adenoma was the second most prevalent tumor followed by cystadenomas and myoepitheliomas. According to this author, WT may be even more scarce than indicated by the literature. Furthermore, apart from this referred study, other two conducted in Brazil, showed WT is not always the second most frequent tumor showing some discrepancy even in the same coun- try (Table 3).

In our analysis, WT affected exclusively the parotid gland with the majority of the cases occurring in males. According to the studies of Ito et al. (17), Oliveira et al. (14), Tian et al. (2), Bello et al. (13), Fonseca et al. (3), Wang et al. (4), Vasconcelos et al. (5), Gao et al. (6), Pinheiro et al. (18) and Shen et al. (9), the parotid gland represents the most prevalent anatomical site of WT with men being the most affected. Tian et al. (2), highlighted an increase in the incidence of WT in females during the last 50 years and a change in the male:female ratio from 10:1 in 1953 to 1.2:1 in 1996. This may be associated with the increase in the number of women with smoking habits in the last decades, which is a risk factor for this lesion.

Only three cases of sublingual glands were observed, in which all were diagnosed as PA. This anatomical site is the most unusual location for benign salivary gland neoplasms. In fact, Ito et al. (17), Oliveira et al. (14), Fonseca et al. (3) and González et al. (8) did not report any involvement of the sublingual gland by benign neoplasms in their studies. Associated with this, we believe that there is a strong tendency that, when affected, the sublingual gland is mainly a site of malignant tumors. Benign neoplasms in minor glands were more prevalent on the palate, followed by the buccal mucosa. PA was the most frequent lesion at both sites, being reported similar results by Wang et al. (4) and Gao et al. (6). Studies that exclusively addressed tumors in minor salivary glands are also in agreement with our results regarding the most common anatomical site and histological 
diagnosis. However, they showed variations regarding the second most common anatomical site in which they reported being the lips or tongue instead of the buccal mucosa $(16,19,20)$.

In our sample, all cases were treated by non-radical surgical excision. Vasconcelos et al. (5), Dalgic et al. (20), Rapidis et al. (21) and Sun et al. (22), also reported that surgery was the treatment of choice for benign salivary gland neoplasms. Overall, there are limited studies published in the literature that present data concerning the treatment of these tumors. This is attributed to the fact that surgery is the gold standard therapy for benign salivary gland neoplasms, being this treatment already very well-established.

CAEXPA is a neoplasm with an epithelial and/or myoepithelial component that develops from primary PA or recurrent tumors. It represents approximately $3.6 \%$ of all salivary gland neoplasms and $12 \%$ of the malignant salivary gland neoplasms $(1,12)$. Larger series studies have revealed variations in the occurrence of CAEXPA. In a research conducted by Tian et al. (2), there were 3,281 cases of PA and 179 cases of CAEXPA, which constituted $5.4 \%$ of PA malignant transformation. In general, other authors indicate that nearly 2.5 to $6.8 \%$ of all PA present malignant transformation $(4,6,10)$. As showed in Table 3, studies in Brazil show variation in the percentage of CAEXPA, however, the transformation rate in general is between 1 and 5\% (3,7,17,23-25). In our analysis, of the 178 cases diagnosed as PA, there was malignant transformation in 7 patients, representing 3.9\% of the cases. History of recurrences of PA prior to the transformation was noted confirming an important characteristic associated with the development of CAEXPA (12).

An important aspect to consider is that the tumors analyzed derived from a medical pathology center (general pathology service), instead of an oral pathology service. It has been shown $(3,25)$ that in medical services the most common location for benign salivary gland neoplasms is the parotid gland in which PA and WT are the most frequent tumors as we observed in the present study. In the other hand, in an oral pathology laboratory most lesions diagnosed are from the minor salivary glands, especially the palate, evidencing a different distribution profile. Furthermore, PA is also the most common tumor in this location, followed by other tumors such as canalicular adenoma, myoepithelioma and basal cell adenoma. The fact that this study was conducted in a medical center also indicates that WT was the second most common tumor as it occurs almost exclusively in the parotid gland as already discussed. Thereby, when analyzing the distribution of salivary gland tumors, the pathology service (general or oral) the lesions were evaluated has to be taken into consideration as it influences the clinicopathological profile of these tumors.

\section{Conclusions}

Our results were similar to those found in the literature. PA was the most common benign neoplasm, occurring mainly in the parotid gland and female patients. Considering the histopathological variety of salivary gland neoplasms, this study contributed to update current knowledge about the clinicopathological characteristics of these tumors, emphasizing its continuous importance for scientific and clinical purposes.

\section{References}

1. Seethala RR, Stenman G. Update from the 4th Edition of the World Health Organization Classification of Head and Neck Tumours: Tumors of the Salivary Gland. Head Neck Pathol. 2017;11:55-67.

2. Tian Z, Li L, Wang L, Hu Y, Li J. Salivary gland neoplasms in oral and maxillofacial regions: a 23-year retrospective study of 6982 cases in an eastern Chinese population. Int J Oral Maxillofac Surg. 2010;39:235-42.

3. Fonseca FP, Carvalho Mde V, de Almeida OP, Rangel AL, Takizawa MC, Bueno AG, et al. Clinicopathologic analysis of 493 cases of salivary gland tumors in a Southern Brazilian population. Oral Surg Oral Med Oral Pathol Oral Radiol. 2012;114:230-39.

4. Wang XD, Meng LJ, Hou TT, Huang SH. Tumours of the salivary glands in northeastern China: a retrospective study of 2508 patients. Br J Oral Maxillofac Surg. 2015;53:132-37.

5. Vasconcelos AC, Nör F, Meurer L, Salvadori G, Souza LB, Vargas PA, et al. Clinicopathological analysis of salivary gland tumors over a 15-year period. Braz Oral Res. 2016;30:S1806-83242016000100208.

6. Gao M, Hao Y, Huang MX, Ma DQ, Chen Y, Luo HY, et al. Salivary gland tumours in a northern Chinese population: a 50year retrospective study of 7190 cases. Int J Oral Maxillofac Surg. 2017;46:343-49.

7. da Silva LP, Serpa MS, Viveiros SK, Sena DAC, de Carvalho Pinho RF, de Abreu Guimarães LD, et al. Salivary gland tumors in a Brazilian population: A 20-year retrospective and multicentric study of 2292 cases. J Craniomaxillofac Surg. 2018;46:2227-33.

8. Campolo González A, Ramírez Skinner H, Vargas Díaz A, León Ramírez A, Goñi Espildora I, Solar González A. Epithelial tumors of salivary glands. Review of 286 pathology reports. Rev Med Chil. 2018;146:1159-66.

9. Shen SY, Wang WH, Liang R, Pan GQ, Qian YM. Clinicopathologic analysis of 2736 salivary gland cases over a 11-year period in Southwest China. Acta Otolaryngol. 2018;138:746-49.

10. Sentani K, Ogawa I, Ozasa K, Sadakane A, Utada M, Tsuya T, et al. Characteristics of 5015 Salivary Gland Neoplasms Registered in the Hiroshima Tumor Tissue Registry over a Period of 39 Years. J Clin Med. 2019;8:566.

11. Mejía-Velázquez CP, Durán-Padilla MA, Gómez-Apo E, Quezada-Rivera D, Gaitán-Cepeda LA. Tumors of the salivary gland in Mexicans. A retrospective study of 360 cases. Med Oral Patol Oral Cir Bucal. 2012;17:e183-9.

12. Mariano FV, Noronha AL, Gondak RO, Altemani AM, de Almeida OP, Kowalski LP. Carcinoma ex pleomorphic adenoma in a Brazilian population: clinico-pathological analysis of 38 cases. Int $\mathrm{J}$ Oral Maxillofac Surg. 2013;42:685-92.

13. Bello IO, Salo T, Dayan D, Tervahauta E, Almangoush A, Schnaiderman-Shapiro A, et al. Epithelial salivary gland tumors in two distant geographical locations, Finland (Helsinki and Oulu) and Israel (Tel Aviv): a 10-year retrospective comparative study of 2,218 cases. Head Neck Pathol. 2012;6:224-31.

14. de Oliveira FA, Duarte EC, Taveira CT, Máximo AA, de Aquino EC, Alencar Rde C, et al. Salivary gland tumor: a review of 599 cases in a Brazilian population. Head Neck Pathol. 2009;3:271-5.

15. Bittar RF, Ferraro HP, Moraes Gonçalves FT, Couto da Cunha MG, Biamino ER. Neoplasms of the salivary glands: analysis of 727 histopathological reports in a single institution. Otolaryngol Pol. 2015;69:28-33. 
16. Abrahão AC, Santos Netto Jde N, Pires FR, Santos TC, Cabral MG. Clinicopathological characteristics of tumours of the intraoral minor salivary glands in 170 Brazilian patients. Br J Oral Maxillofac Surg. 2016;54:30-4.

17. Ito FA, Ito K, Vargas PA, de Almeida OP, Lopes MA. Salivary gland tumors in a Brazilian population: a retrospective study of 496 cases. Int J Oral Maxillofac Surg. 2005;34:533-6.

18. Pinheiro J, Sá Fernandes M, Pereira AR, Lopes JM. Histological Subtypes and Clinical Behavior Evaluation of Salivary Gland Tumors. Acta Med Port. 2018;31:641-7.

19. Dhanuthai K, Boonadulyarat M, Jaengjongdee T, Jiruedee K. A clinico-pathologic study of 311 intra-oral salivary gland tumors in Thais. J Oral Pathol Med. 2009;38:495-500.

20. Dalgic A, Karakoc O, Aydin U, Hidir Y, Gamsizkan M, Karahatay S, Gerek M. Minor salivary gland neoplasms. J Craniofac Surg. 2014;25:e289-91.

21. Rapidis AD, Stavrianos S, Lagogiannis G, Faratzis G. Tumors of the submandibular gland: clinicopathologic analysis of 23 patients. J Oral Maxillofac Surg. 2004;62:1203-8.

22. Sun G, Yang X, Tang E, Wen J, Lu M, Hu Q. The treatment of sublingual gland tumours. Int J Oral Maxillofac Surg. 2010;39:863-8. 23. Reinheimer A, Vieira DS, Cordeiro MM, Rivero ER. Retrospective study of 124 cases of salivary gland tumors and literature review. J Clin Exp Dent. 2019;11:e1025-32.

24. Morais Mde L, Azevedo PR, Carvalho CH, Medeiros L, Lajus T, Costa Ade L. Clinicopathological study of salivary gland tumors: an assessment of 303 patients. Cad Saude Publica. 2011;27:1035-40. 25. Cunha JL, Coimbra AC, Silva JV, Nascimento IS, Andrade ME, Oliveira CR, et al. Epidemiologic analysis of salivary gland tumors over a 10-years period diagnosed in a northeast Brazilian population. Med Oral Patol Oral Cir Bucal. 2020;25:e516-22.

\section{Funding}

None declared.

\section{Conflict of interest}

The authors state that they have no conflict of interest.

\section{Ethics}

The study was approved by the Research Ethics Committee of the Cancer Hospital of Pernambuco, Recife, Brazil (protocol $n^{\circ}$ 2.774.008).

\section{Authors contributions}

Breno WJ de Santana was responsible for the data curation, methodology and writing-original draft. Leorik P da Silva for the conceptualization, data curation and writing-original draft. Marianna S Serpa for the data curation and writing-review and editing. Mariana de A Borges and Sérgio Ricardo S de Moura for the data curation and methodology. Márcia MF da Silveira and Ana Paula V Sobral for the conceptualization and writing-review and editing of the manuscript. 